\title{
Open-field behavior, emotionality during fear conditioning, and fear-motivated instrumental performance
}

\author{
RONALD LEY \\ State University of New York at Albany, 1400 Washington Avenue, Albany, New York 12222
}

\begin{abstract}
Open-field activity and open-field defecation measures of young-adult hooded rats were made prior to a series of 35 fear-conditioning trials. Although activity and defecation were not correlated, defecation measures made during fear conditioning were found to be negatively correlated with open-field activity and positively correlated with open-field defecation. These findings were interpreted as support for the hypothesis that open-field emotionality is an index of general drive. Subsequent fear-motivated instrumental hurdle-jump scores were found to be unrelated to open-field defecation but positively correlated with open-field activity and defecation during fear conditioning.
\end{abstract}

Open-field activity and open-field defecation have been widely used as dependent variables in early experience studies. Although these responses may be sensitive to a wide range of stimuli, open-field behavior has also been studied as a dispositional variable independent of experimental manipulations of environmental variables. Active and inactive strains of rats have been bred as well as emotional and unemotional strains (Hall, 1938; Hall, 1941).

If emotionality, as a dispositional characteristic, contributes to an animal's general drive level, open-field behavior should correlate with emotionality during fear conditioning and with fear-motivated behavior. The purpose of the present study was to investigate the relationship of open-field behavior, independent of previous systematic early experience treatments, with emotionality during fear conditioning and with performance of an instrumental fear-motivated response.

\section{METHOD}

\section{Subjects}

The subjects were 84 male hooded rats from the colony maintained at the Psychology Department of Syracuse University, 91-128 days of age on their 1st experimental day; average age was 108 days.

\footnotetext{
Apparatus

The open field consisted of a gray rectangular wooden table top, $88.26 \times 45.08 \mathrm{~cm}$, the surface of which was marked off in $15.24-\mathrm{cm}$ squares and spaced approximately $3.81 \mathrm{~cm}$ apart. The two short sides and one long side of the surface were enclosed by $50.8-\mathrm{cm}$ high gray plywood walls. Primary source of illumination was provided by a $40-\mathrm{W}$ incandescent lamp mounted at the top center of the rear wall.

Fear conditioning was performed in two separate white wooden framed shockboxes, the interior dimensions of which were $24.76 \mathrm{~cm}$ long $\times 6.35 \mathrm{~cm}$ wide $\times 12.70 \mathrm{~cm}$ high. The floor of each box consisted of $21.24-\mathrm{cm}$ brass welding rods spaced $1.11 \mathrm{~cm}$ apart, through which a $115-\mathrm{V}$ electric current (UCS) could be
}

delivered at the rate of two impulses per grid per second. A 100,000 -ohm resistor was in series with each subject. Hinged to the rear wall of each shockbox was a $30.48-\mathrm{cm}$-high box, the hardware cloth bottom of which served as the ceiling of the shockbox. Mounted $1.90 \mathrm{~cm}$ above the hardware cloth bottom was a pane of opal glass which provided diffuse transmission of light from the tunnel to the interior of the shockbox. Concealed within the tunnel were the CS, a $40-W$ incandescent lamp situated $20.32 \mathrm{~cm}$ above the opal glass; and the intertrial light, a $71 / 2-W$ incandescent lamp situated $25.40 \mathrm{~cm}$ above the opal glass. The illumination provided by the CS was approximately $120 \mathrm{fc}$, and the intertrial illumination $71 / 2$ fc.

The hurdle-jump apparatus consisted of two compartments separated by a $1.90-\mathrm{cm}$ partition containing a guillotine door $6.35 \mathrm{~cm}$ wide $x 7.62 \mathrm{~cm}$ high which rested on a $5.08-\mathrm{cm}$-high hurdle. The startbox was built to be identical to the shockboxes, whereas the safebox was gray and had a plywood floor. Raising of the manually operated guillotine door closed a switch which resulted in the simultaneous activation of the CS and Hunter klockounter. A second switch was located beneath the safebox floor. The weight of an animal on the floor closed the switch, which simultaneously turned off the CS and stopped the klockounter.

\section{Procedure}

The data of the present study were taken from those of a larger study addressed to the determination of the effects of irrelevant drives on fear-motivated behavior (Ley, 1965). During the first phase of this study, open-field behavior was measured on the first 2 experimental days. Each of the 84 subjects was allowed $5 \mathrm{~min}$ in the open field per day during which activity was measured in terms of number of squares entered, and defecation in terms of number of boluses defecated. The subjects were also given $71 / 2 \mathrm{~min}$ of handling and $20 \mathrm{~min}$ of exploration of the hurdle-jump apparatus on each of these days.

The second phase of the study was carried out on the 3rd experimental day during which each subject was given 35 fear-conditioning trials. Each trial began with the presentation of the CS of 6 sec duration. Four seconds after the onset of the CS, the UCS was presented for $2 \mathrm{sec}$, with the CS and UCS terminating simultaneously. Intertrial interval was 2 min. A measure of emotionality during fear conditioning, in terms of number of boluses defecated, was made at the end of the 35 trials.

The third phase of the experiment, which involved the measurement of the fear-motivated hurdle-jump response, was carried out on the 10th and 11th experimental days. For the purposes of the larger study, this phase was preceded by 7 days of 
23-h limited-time food and water deprivation. On the 2 hurdle-jump days, subjects were tested under one of six different drive levels. One of the six groups of 14 subjects was run as a control; that is, their hurdle-jump performance was measured under conditions of satiation rather than deprivation. Since this condition was consonant with those under which subjects were fear conditioned, the data of the third phase of the present study are limited to the 14 subjects of the control group.

Each of the 25 trials of Days 10 and 11 consisted of placing each subject in the startbox of the hurdle-jump apparatus, $10 \mathrm{sec}$ after which the experimenter raised the guillotine door which simultaneously activated a klockounter. The UCS was not presented during test trials. When a subject jumped the hurdle, the depression of the floor switch of the safebox terminated the CS and stopped the klockounter, thus providing a measure of the response latency. The guillotine door was lowered following the subject's entrance into the safebox, where the subject remained for $10 \mathrm{sec}$ after which he was removed and placed in a holding cage before being returned to the startbox for the next trial. Response latencies for each subject on each trial were converted into reciprocals, and mean reciprocals for each subject were computed in blocks of five trials, thus providing for five blocks of trials the 1st and 2 nd days of testing.

\section{RESULTS}

The data of Table 1 indicate that open-field defecation, as measured in terms of boluses defecated and a boluses-to-body-weight ratio, was not found to be correlated with open-field activity as measured by number of squares entered. However, boluses defecated in the open field were found to be positively correlated with both measures of emotionality during fear conditioning: number of boluses defecated, $r(82)$ $=.24, \mathrm{p}<.05$; and boluses-to-body weight ratio, $\mathrm{r}(82)=.22, \mathrm{p}<.05$. Defecation scores on the 2 nd day of open-field testing were not included in the correlational analysis because of the sharp drop in defecation from the 1st test day ( $M$ number of boluses $=3.32$ ) to the 2 nd test day ( $\mathrm{M}$ number of boluses = $.40), \mathrm{t}=12.90, \mathrm{df}=83, \mathrm{p}<.001$.

Although activity also decreased from the 1st open-field test day (M squares entered $=79.5$ ) to the 2nd open-field test day $(M$ squares entered $=62.9), \mathrm{t}$ $=6.41, \mathrm{df}=83, \mathrm{p}<.001$, all subjects were active on the 2nd day; whereas only 23 subjects defecated on the 2nd day. Activity on Day 1 was found to be correlated with activity on Day $2(r=.21, p<.05)$, and activity on both days was found to be correlated with the activity scores of Days 1 and 2 combined. Although activity on Day 1 was not found to be correlated with emotionality during fear conditioning, activity on Day 2 correlated with emotionality in terms of the number of boluses defecated $(r=-.19$, $p<.05)$ with the boluses-to-body-weight ratio $(r=-.25, p<.05)$. The combined activity measure was found to be unrelated to either of the emotionality measures during fear conditioning.

From Table 2 it can be seen that neither of the measures of open-field defecation was found to be correlated with the speed measures of the fear-motivated hurdle-jump response. However, a scattergram plot indicated that there was considerable departure from linearity, in which low- and high-defecating subjects had lower hurdle-jump speeds as compared with moderate-defecating subjects. The mean hurdle-jump speed on Days 1 and 2 combined for the four subjects which defecated two or fewer boluses $(M=1)$ was .35 ; the mean speed for six subjects which defecated three or four boluses $(M=3.7)$ was .67 ; and the mean speed for four subjects which defecated five or more boluses $(M=5.7)$ was .26 . A correlation ratio computed for these data resulted in an eta of $.34, p>.05$.

Open-field activity on Day 1 was found to be correlated with the fear-motivated response on the 1st day of hurdle-jumping $(r=.48, p<.05)$ and both hurdle-jump test days combined $(r=.47, p<.05)$, although the correlations for open-field activity on Day 2 fell short of significance. The combined open-field activity measures resulted in positive correlations with hurdle-jump performance (Day $1, r$ $=.64$; Day 2, $\mathrm{r}=.69$; Days 1 and $2, \mathrm{r}=.68$ ).

Table 1

Correlation Coefficients Between Measures of Open-Field Behavior and Measures of Emotionality During Fear Conditioning ( $\mathrm{N}=84)$

\begin{tabular}{|c|c|c|c|c|c|c|}
\hline & \multicolumn{4}{|c|}{ Open-Field Behavior } & \multicolumn{2}{|c|}{$\begin{array}{l}\text { Defecation During } \\
\text { Fear Conditioning }\end{array}$} \\
\hline & \multirow{2}{*}{$\begin{array}{c}\text { Boluses (Day } 1) \\
\div \text { body weight }\end{array}$} & \multicolumn{3}{|c|}{ Squares } & \multirow{2}{*}{$\begin{array}{l}\text { Boluses } \\
\text { (Day 3) }\end{array}$} & \multirow{2}{*}{$\begin{array}{c}\text { Boluses (Day } 3 \text { ) } \\
\div \text { body weight } \\
\end{array}$} \\
\hline & & Day 1 & Day 2 & Days $1+2$ & & \\
\hline $\begin{array}{l}\text { Open-field defecation } \\
\text { Boluses (Day } 1) \\
\text { Boluses (Day } 1) \div \text { body weight }\end{array}$ & $.85^{* *}$ & $\begin{array}{l}-.11 \\
-.02\end{array}$ & $\begin{array}{l}-.07 \\
-.09\end{array}$ & $\begin{array}{l}-.09 \\
-.05\end{array}$ & $\begin{array}{l}.24^{*} \\
.17\end{array}$ & $\begin{array}{l}.22 * \\
.19 *\end{array}$ \\
\hline $\begin{array}{l}\text { Open-field activity } \\
\text { Squares entered (Day 1) } \\
\text { Squares entered (Day 2) } \\
\text { Squares entered (Days 1+2) }\end{array}$ & & & $.21 *$ & $\begin{array}{l}.70^{* *} \\
.80^{* *}\end{array}$ & $\begin{array}{l}.07 \\
-.19 * \\
-.06\end{array}$ & $\begin{array}{l}.11 \\
-.25^{*} \\
-.06\end{array}$ \\
\hline $\begin{array}{l}\text { Defecation during fear conditioning } \\
\text { Boluses (Day 3) }\end{array}$ & & & & & & $.92 * *$ \\
\hline
\end{tabular}

${ }^{*} p<.05 \quad{ }^{* *} p<.01$ 
Emotionality during fear conditioning in terms of boluses defecated resulted in positive correlations with hurdle-jump performance (Day $1, \mathrm{r}=.61$; Day $2, \mathrm{r}=$ .64 ; Days 1 and 2, $\mathrm{r}=.63$ ) as did the boluses-to-body-weight ratio during fear conditioning (Day 1, $\mathrm{r}=.60$; Day 2, $\mathrm{r}=.57$; Days 1 and 2, $\mathrm{r}=.57$ ).

\section{DISCUSSION}

Although the correlations between the measures of open-field activity and open-field defecation were not significant, all these correlations were negative, a trend which is consistent with the generally accepted relationship between these variables (e.g., Snowdon, Bell, \& Henderson, 1964). To the extent that defecation during fear conditioning is an index of the strength of the conditioned emotional response, the positive correlations between open-field defecation and defecation during fear conditioning support the hypothesis that emotionality can be viewed as a dispositional characteristic which contributes to general drive. The negative correlation between activity on Day 2 and the boluses-to-body-weight ratio during fear conditioning also supports the hypothesis, if, as is generally accepted, activity and emotionality are inversely related.

The findings which indicate that open-field defecation is not correlated with the fear-motivated instrumental hurdle-jump response do not support the general drive hypothesis. The inverted $\mathrm{U}$ relationship suggested by the data would be consistent with Denenberg's (1964) hypothesis that the relationship between performance and emotional reactivity is dependent upon the level of difficulty of the learning task. Avoidance conditioning (a fear-motivated learning task) is viewed by Denenberg as a task of moderate difficulty in which optimal performance is favored by moderate emotional reactivity and minimal performance by both low and high emotional reactivity, i.e., an inverted $U$ relationship between performance and emotionality.

If the level of performance of the hurdle-jump response is a function of the strength of the conditioned emotional response, the positive correlations between the defecation measures during fear conditioning and hurdle-jump performance suggest that defecation during fear conditioning is an index of the strength of the conditioned emotional response. In view of the positive correlations between open-field activity and hurdle-jump performance, it would appear that hurdle-jumping is dependent upon more than the strength of the conditioned emotional response. Although activity and emotionality are inversely related, it may be that the nature of the hurdle-jump response is such that activity facilitates the acquisition and perhaps the performance of the response. Subjects that react to their environment by moving about increase the probability of their making the response which removes them from the fear-inducing environment, thus facilitating the learning of the instrumental hurdle jump.

Table 2

Correlation Coefficients Between Measures of Open-Field Behavior, Measures of Emotionality During Fear Conditioning, and Fear-Motivated Hurdle-Jump Performance $(N=14)$

\begin{tabular}{|c|c|c|c|}
\hline & \multicolumn{3}{|c|}{ Speed } \\
\hline & $\begin{array}{c}\text { Day } \\
1\end{array}$ & $\begin{array}{c}\text { Day } \\
2\end{array}$ & $\begin{array}{l}\text { Days } \\
1+2 \\
\end{array}$ \\
\hline $\begin{array}{l}\text { Open-field defecation } \\
\text { Boluses (Day } 1 \text { ) } \\
\text { Boluses (Day } 1) \div \text { body weight }\end{array}$ & $\begin{array}{r}.01 \\
-.10\end{array}$ & $\begin{array}{l}-.12 \\
-.16\end{array}$ & $\begin{array}{l}-.06 \\
-.07\end{array}$ \\
\hline $\begin{array}{l}\text { Open-field activity } \\
\text { Squares entered (Day 1) } \\
\text { Squares entered (Day 2) } \\
\text { Squares entered (Days 1 }+2 \text { ) }\end{array}$ & $\begin{array}{l}.48^{*} \\
.32 \\
.64^{* *}\end{array}$ & $\begin{array}{l}.45 \\
.44 \\
.69 * *\end{array}$ & $\begin{array}{l}.47 * \\
.39 \\
.68 * *\end{array}$ \\
\hline $\begin{array}{l}\text { Defecation during fear conditioning } \\
\text { Boluses (Day } 3 \text { ) } \\
\text { Boluses (Day } 3) \div \text { body weight }\end{array}$ & $\begin{array}{l}.61^{* *} \\
.56^{*}\end{array}$ & $\begin{array}{c}.64^{* *} \\
.57^{*} \\
\end{array}$ & $\begin{array}{l}.63^{* *} \\
.57^{*}\end{array}$ \\
\hline
\end{tabular}

\section{REFERENCES}

Denenberg, V. H. Critical periods, stimulus input, and emotional reactivity: A theory of infantile stimulation. Psychological Review, 1964, 71, 335-351.

Hall, C. S. The inheritance of emotionality. American Scientist, 1938, 26, 17-27.

HALl, C. S. Temperament: A survey of animal studies. Psychological Bulletin, 1941, 38, 909-943.

LEY, R. Effects of food and water deprivation on the performance of a response motivated by acquired fear. Journal of Experimental Psychology, 1965, 69, 583-589.

Snowdon, C. T., Bell, D. D., \& Henderson, N. D. Relationships between heart rate and open-field behavior. Journal of Comparative and Physiological Psychology, 1964, 58, $423-426$.

(Received for publication August 8, 1975.) 